\title{
Ocular findings associated with a 3 base pair deletion in the peripherin-RDS gene in autosomal dominant retinitis pigmentosa
}

\author{
John J Wroblewski, John A Wells III, Anja Eckstein, Fred W Fitzke, Chris Jubb, \\ T Jeffrey Keen, Chris F Inglehearn, Shomi S Bhattacharya, Geoffrey B Arden, Marcelle R Jay, \\ Alan C Bird
}

\begin{abstract}
Affected members of a family with autosomal dominant retinitis pigmentosa were found to have a 3 base pair deletion at codon 118 or 119 of the retinal degeneration slow gene. This mutation causes the loss of a highly conserved cysteine residue in the predicted third transmembrane domain of peripherin-rds, a photoreceptor specific structural glycoprotein localised to both rod and cone outer segment disc membranes. Four of these individuals underwent detailed clinical, psychophysical, and electroretinographic testing in order to characterise their photoreceptor dysfunction. Nyctalopia was reported early in the second decade by all patients. Global rod and cone dysfunction was recorded by the third decade with severe reduction of both photopic and scotopic function by age $\mathbf{3 0}$ years. This retinal degeneration slow gene mutation may lead to the primary loss of both rod and cone photoreceptor function.
\end{abstract}

(BrF Ophthalmol 1994; 78: 831-836)

Retinitis pigmentosa denotes a group of hereditary retinal disorders, causing degeneration of retinal photoreceptors which begins in the midperipheral fundus. Classically, the diagnosis of retinitis pigmentosa has been used to describe an unknown number of clinically similar but genetically distinct conditions, ${ }^{12}$ causing a recognisable pattern of functional and ophthalmoscopic changes. Population surveys have reported that 22 to $25 \%$ of all cases of retinitis pigmentosa are inherited in an autosomal dominant fashion. ${ }^{34}$ Since the first recognition that mutations in the rhodopsin gene caused autosomal dominant retinitis pigmentosa ${ }^{56}$ more than 30 mutations have been detected in the rhodopsin gene, and it appears that this gene accounts for about $25 \%$ of autosomal dominant retinitis pigmentosa. ${ }^{7-10}$

In several families with autosomal dominant disease, there is no linkage with markers in the long arm of chromosome 3 , " and genes other than that for rhodopsin have been shown to be responsible for autosomal dominant retinitis pigmentosa. ${ }^{12-15}$ One of these is the retinal degeneration slow gene (RDS) on chromosome $6 \mathrm{p},{ }^{13-15}$ which is of particular interest since this gene is responsible for the photoreceptor degeneration in the retinal degeneration slow mouse. ${ }^{1617}$ The product of the RDS gene, peripherin-rds, is a photoreceptor specific glycoprotein that is localised to the outer segment disc membranes of both rods and cones, and is thought to be essential for normal retinal photoreceptor outer segment disc assembly and orientation. ${ }^{18-20}$

Recently it has been reported that a wide variety of phenotypes are associated with RDS gene mutations including central as well as peripheral dystrophies, and disease with outer retinal atrophy as well as those presenting with accumulation of material at the level of the retinal pigment epithelium. ${ }^{21-23}$ One of these mutations, a 3 base pair deletion at codon 118 or 119 leading to the loss of a highly conserved cysteine residue in the predicted third transmembrane domain of peripherin-rds (cysteine $118 / 119$ deletion), has been identified as the cause of autosomal dominant retinitis pigmentosa in families of Irish origin. ${ }^{131421} \mathrm{We}$ describe the clinical, psychophysical, and electroretinographic findings of affected members in one of these families. ${ }^{21}$

\section{Patients and methods}

Families with peripheral retinal degenerations and clear evidence of autosomal dominant inheritance were screened for genetic mutations in the RDS gene. Affected members of one family were found to have a cysteine 118/119 deletion mutation. ${ }^{21}$ This mutation was not found by heteroduplex analysis in 60 unrelated control subjects with normal vision. ${ }^{24}$

\section{CLINICAL EVALUATION}

Patients were questioned as to their subjective complaints of poor night vision, decreased central acuity, and constriction of visual field. Measurement of Snellen visual acuity, complete ophthalmoscopic examination, colour fundus photographs, and fluorescein angiography were performed to document the retinal findings.

\section{PSYCHOPHYSICS}

Static threshold perimetry was used to measure retinal sensitivities in one eye of all patients. A modified Humphrey visual field analyser ${ }^{25}$ using the 30-2 and 30/60-2 programs was used under photopic and scotopic conditions. Photopic visual field testing was performed using a white Goldmann size III test spot. Scotopic perimetry was performed with a dilated pupil after 45 minutes of dark adaptation using blue $(450 \mathrm{~nm})$ and red $(650 \mathrm{~nm})$ Goldmann size V test stimuli to isolate rod and cone responses respectively. 
Figure 1 Pedigree shows males (D) and female $(\mathbf{O})$ known to be affected in a family with autosomal dominant retinitis pigmentosa. Arrow ( indicates proband. Bar= examined by the authors.

Diagonal line $=$ the patient is deceased.

I

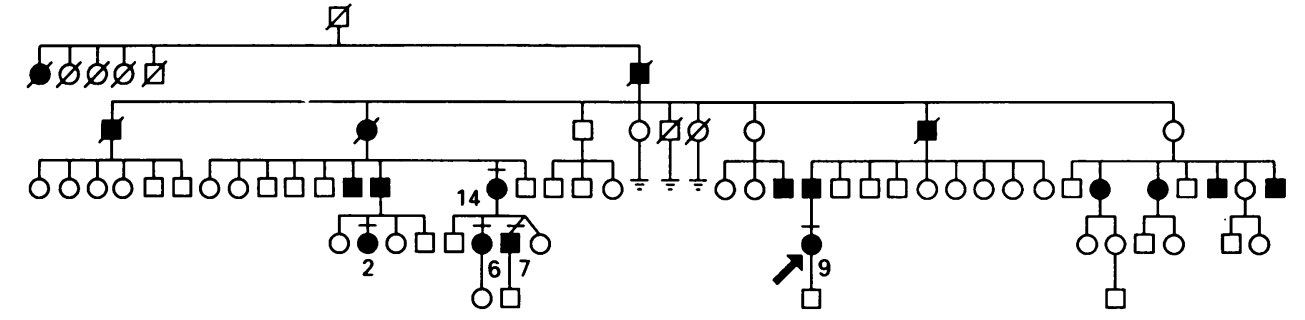

Affected on history

Affected and examined

Dark adaptometry was performed by measuring recovery of retinal sensitivity to white Goldmann size III and V test stimuli at two locations eccentric to fixation after intense light adaptation of $7 \cdot 5$ Troland seconds sufficient to bleach $95 \%$ of rhodopsin. ${ }^{26}$ Baseline dark adapted sensitivity thresholds were established before bleaching. Measurements were continued until prebleach thresholds were reached.

\section{COLOUR VISION}

Colour contrast sensitivity was measured by a system fully described elsewhere. ${ }^{27}$ The minimum colour contrast between letter/annulus and background at which identification of the letter/ annulus is possible is $6 \%$ centrally and $25 \%$ peripherally $\left(22^{\circ}\right.$ of eccentricity) for the protan, deutan, and tritan colour confusion axes in normal subjects.

\section{ELECTRORETINOGRAPHY}

The electroretinogram was recorded using standard testing protocols ${ }^{28} 29$ with gold foil electrodes and a Grass PS22 stroboscope as a stimulator. Further electroretinographic responses were obtained using a series of coloured flashes against different coloured backgrounds. Green $(550 \mathrm{~nm})$ and red $(660 \mathrm{~nm})$ light emitting diodes were used as a stimulus against an opposite background. This system has been fully described elsewhere. ${ }^{30}$ The pattern evoked electroretinogram was also recorded as described in other reports. ${ }^{31}$

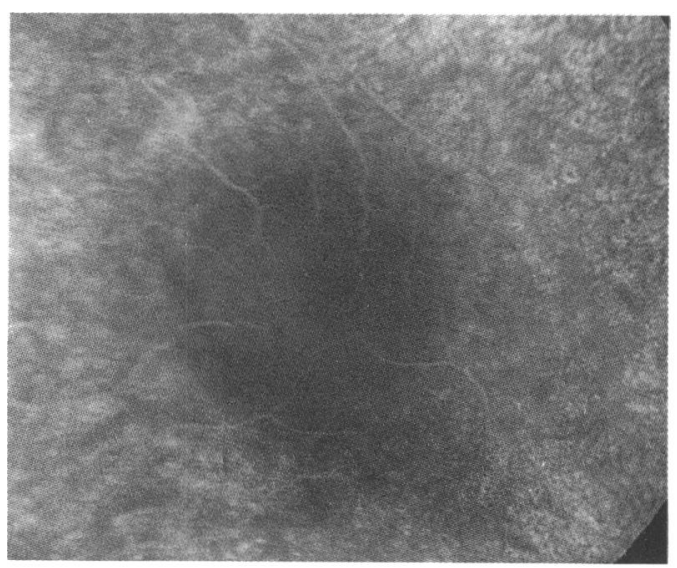

Table 1 Age at examination, age at onset of symptoms, and visual acuity of subjects included in the study

\begin{tabular}{|c|c|c|c|c|c|}
\hline \multirow[b]{2}{*}{ Subject } & \multirow{2}{*}{$\begin{array}{l}\text { Age at } \\
\text { examination } \\
\text { (years) }\end{array}$} & \multicolumn{2}{|c|}{$\begin{array}{l}\text { Onset of symptoms } \\
\text { (years) }\end{array}$} & \multicolumn{2}{|c|}{ Visual acuity } \\
\hline & & $\begin{array}{l}\text { Night } \\
\text { vision }\end{array}$ & $\begin{array}{l}\text { Visual } \\
\text { field }\end{array}$ & $\begin{array}{l}\text { Right } \\
\text { eye }\end{array}$ & $\begin{array}{l}\text { Left } \\
\text { eye }\end{array}$ \\
\hline $\begin{array}{l}\text { V-2 } \\
\text { V-6 } \\
\text { V-7 } \\
\text { V-9 }\end{array}$ & $\begin{array}{l}30 \\
24 \\
29 \\
22\end{array}$ & $\begin{array}{l}<10 \\
<10 \\
<10 \\
<10\end{array}$ & $\begin{array}{l}13 \\
24 \\
11 \\
20\end{array}$ & $\begin{array}{l}6 / 12 \\
6 / 9 \\
6 / 18 \\
6 / 9\end{array}$ & $\begin{array}{l}6 / 12 \\
6 / 9 \\
6 / 9 \\
6 / 12\end{array}$ \\
\hline
\end{tabular}

\section{Results}

Of the family shown to have a cysteine $118 / 119$ deletion mutation, 18 members are known to be affected (Fig 1). All affected members were aware of difficulty with night vision by the age of 10 years, and reduced visual fields during the second or third decades of life (Table 1). Reading vision deteriorated after the age of 50 years, and the oldest patient examined had no useful vision at the age of 60 years. By the third decade of life there was irregularity of pigmentation at the level of the retinal pigment epithelium in the midperipheral fundus which was confirmed by fluorescein angiography (Fig 2A), but little intraretinal pigmentation. Patient $\mathrm{V}-2$ also had mild macular oedema (Fig 2B). By 60 years there was profound atrophy of the retina and choroid.

There was sufficient residual function in four members between the ages of 22 and 30 years $(\mathrm{V}-2, \mathrm{~V}-6, \mathrm{~V}-7, \mathrm{~V}-9)$ to characterise the loss (Table 1). In all the central sensitivities was within 2 log units of normal (Figs 3, 4) except in case $\mathrm{V}-7$. In $\mathrm{V}-7$ cone and rod thresholds were

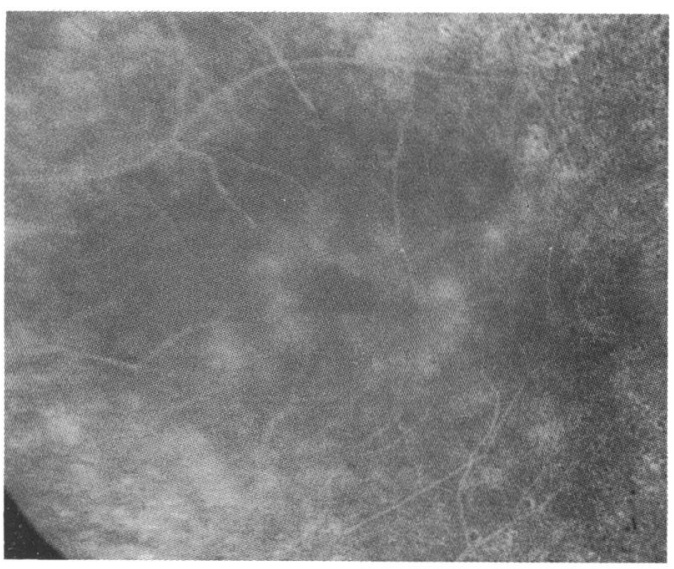

Fig $2 B$

Figure 2 (A) Angiogram of V-9 confirms widespread subtle retinal pigment epithelial alteration. (B) Fluorescein angiogram of patient $V-2$ revealing cystoid macular oedema. 
Figure 3 Scotopic

perimetry of the central $60^{\circ}$

with a blue $(450 \mathrm{~nm})$

Goldmann size $V$ test

stimulus $(A, C, E)$ and of

the central $30^{\circ}$ with a red

$(650 \mathrm{~nm})$ test stimulus

$(B, D)$. (A) Patients V-2;

$(B, C)$ patient $V-6 ; 44(E, F)$

patient $V-9$.

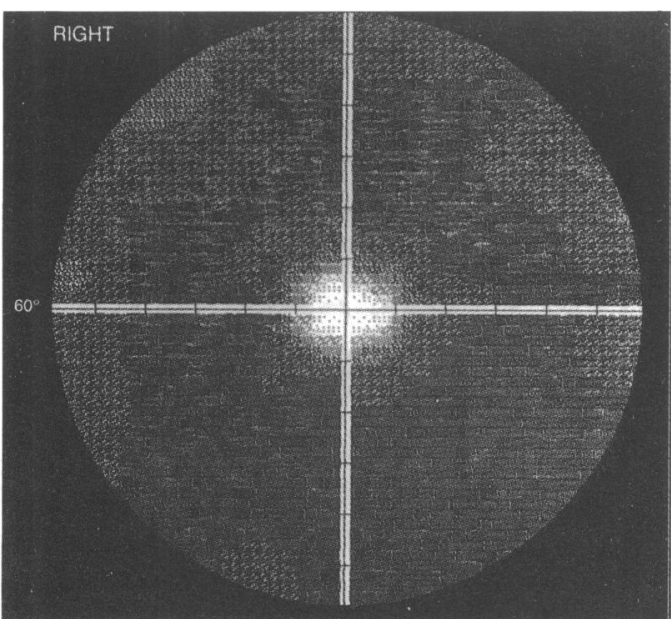

Fig $3 A$

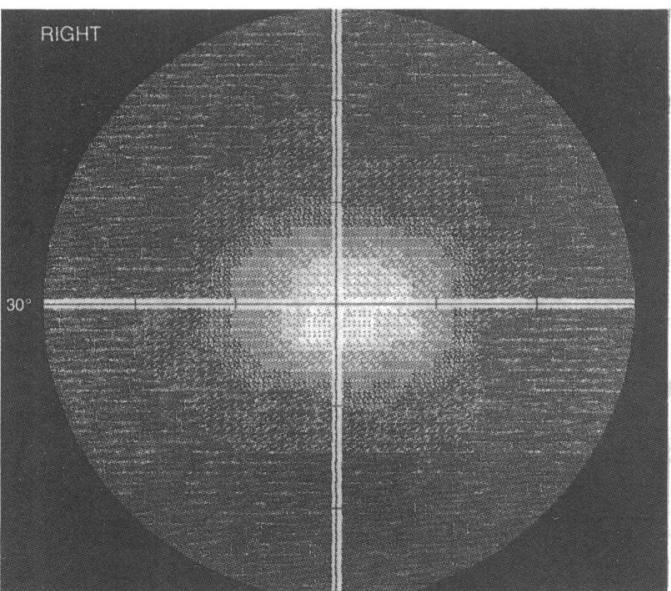

Fig $3 B$

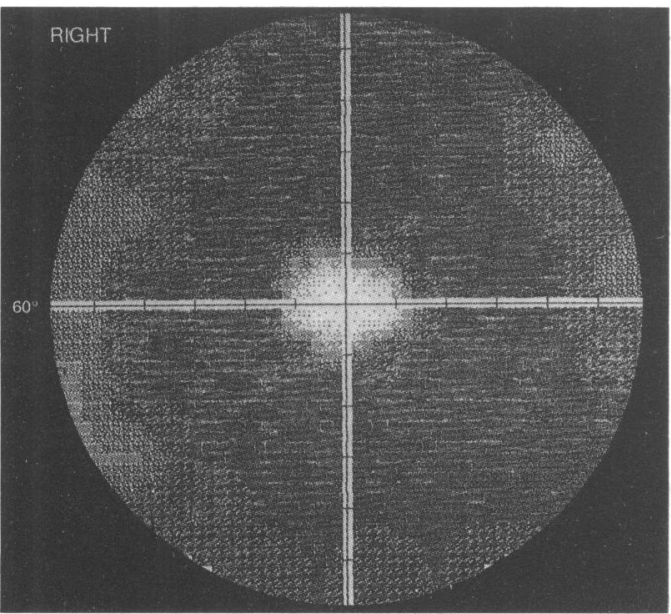

Fig $3 C$

elevated by 2 and 3-5 log units respectively. Depression of sensitivities was less marked under photopic than under scotopic conditions. and cone function was detectable throughout the visual field in two subjects (V-2, V-9), depression of cone sensitivities of 1-2 log units being less marked than those of rods ( $1-4 \log$ units). In the other two little function was detectable outside $9^{\circ}$. Recovery from bleach was recorded at two paracentral points in each subject (Fig 4). At $3^{\circ}$ of eccentricity the prebleach thresholds were elevated by 1-2 log units, the rod-cone break occurred at the normal time and final thresholds were achieved by 45 minutes. In V-2 at $9^{\circ}$ of

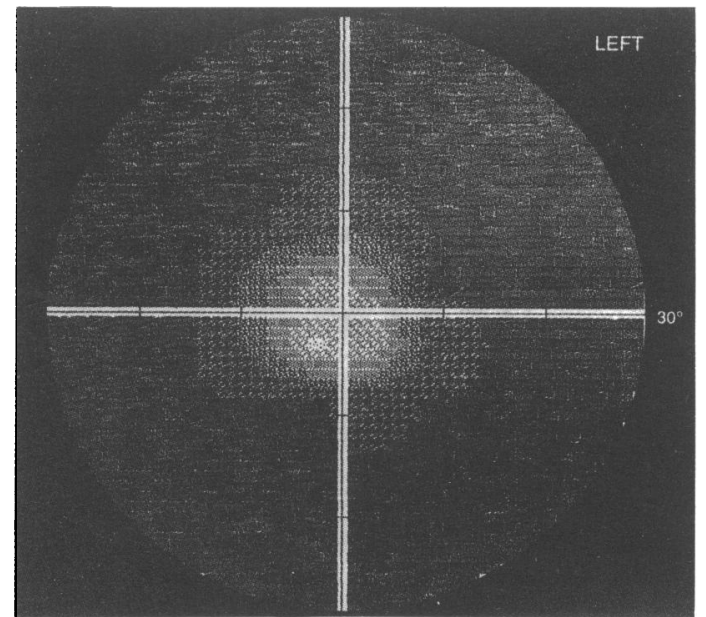

Fig $3 D$

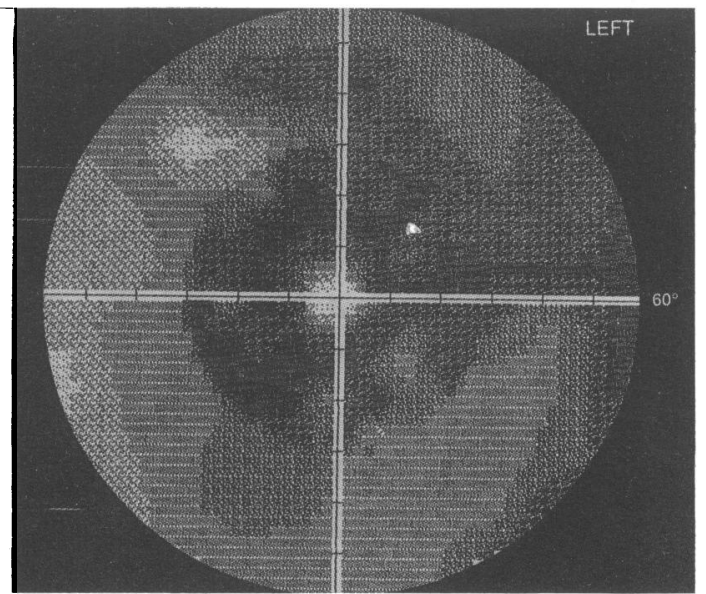

Fig $3 E$

eccentricity the prebleach threshold was elevated by $4 \log$ units and the recovery was monophasic without evidence of rod contribution.

Colour contrast sensitivities were normal centrally in all four subjects but beyond $6^{\circ}$ the objects were not seen at $100 \%$ contrast (Fig 5 ).

In $\mathrm{V}-7$, the electroretinogram was extinguished (Fig 6) and the pattern electroretinogram was just detectable (Fig 7). The electroretinograms were severely depressed in the other three for every testing condition. Minimal cone responses were registered with the $30 \mathrm{~Hz}$ flicker and to a red $(660 \mathrm{~nm})$ flash on a green $(550 \mathrm{~nm})$ background. The pattern electroretinogram was also abnormal, the P50 amplitude being reduced to $50 \%$ of the normal value.

\section{Discussion}

In our family with a cysteine $118 / 119$ del mutation in the RDS gene, affected members consistently had early onset nyctalopia, and a mild reduction of central acuity with advanced visual field constriction by the third decade of life. The findings are characteristic of retinitis pigmentosa and contrast with central retinal dystrophies which have been recorded with other mutations in the RDS gene. ${ }^{21} 22$

The disease appears to be more severe than implied by initial description by Farrar et al of mild functional loss and late onset of symptoms with this 3 base pair deletion ${ }^{1314}$ although the findings are qualitatively similar. Nightblind- 

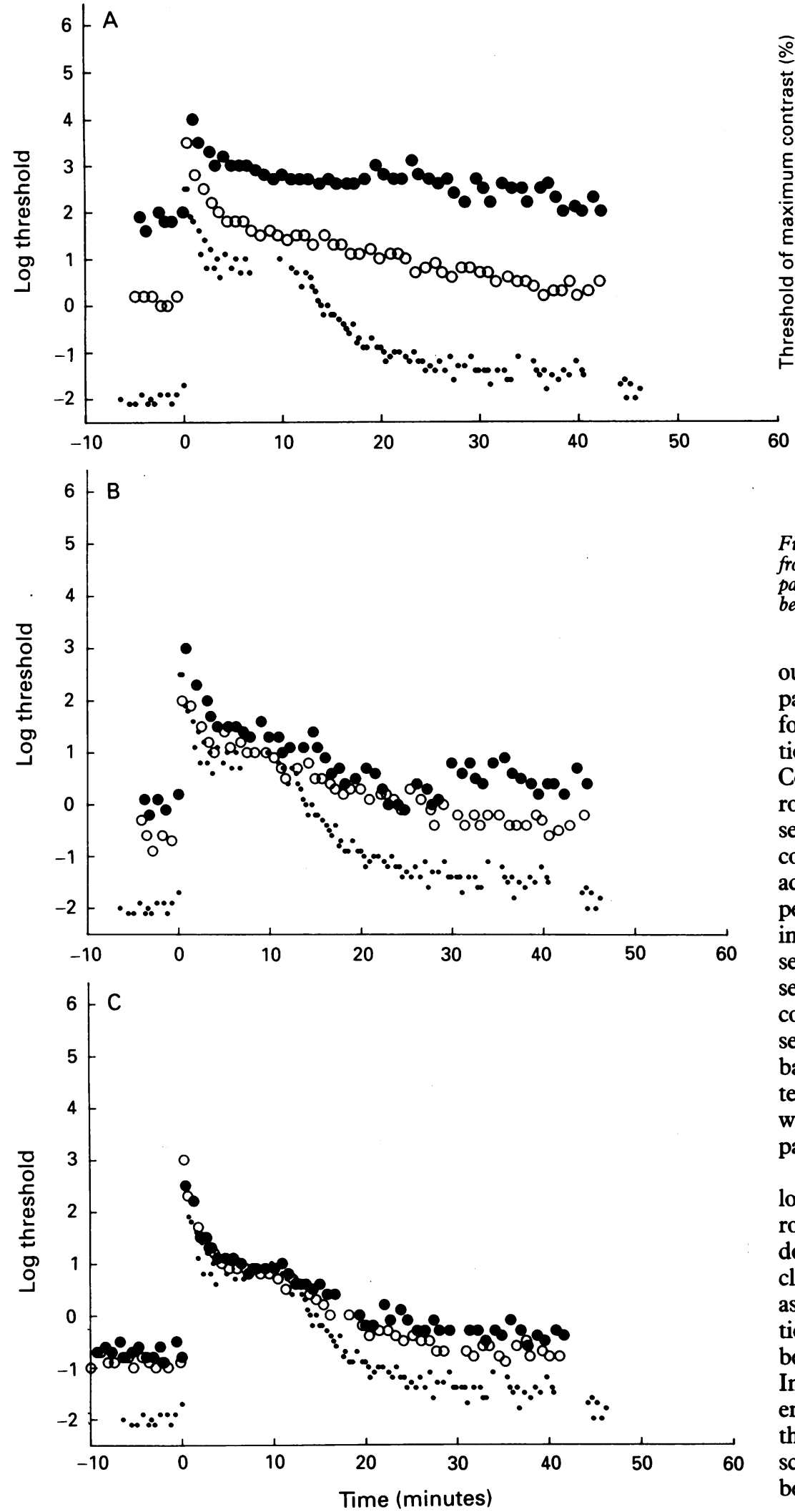

Figure 4 Dark adaptation curves. (A) Patient V-2, at $3^{\circ}(O)$ and $9^{\circ}(O)$ from fixation; $(B)$ patient $V-6$ at $3^{\circ}(\mathrm{O})$ and $90^{\circ}(\mathbf{O})$ from fixation; $(C)$ patient $V-9$ both symbols at $3^{\circ}$ from fixation. The small symbols indicate normal recovery from bleach at $3^{\circ}$ of eccentricity. ness was described as occurring in the fourth decade with rod and cone responses lost by the RP. 32-34 Some variability of disease was detected in our family as is common in autosomal dominant disease, and the inconsistency may be due to chance alone. Testing

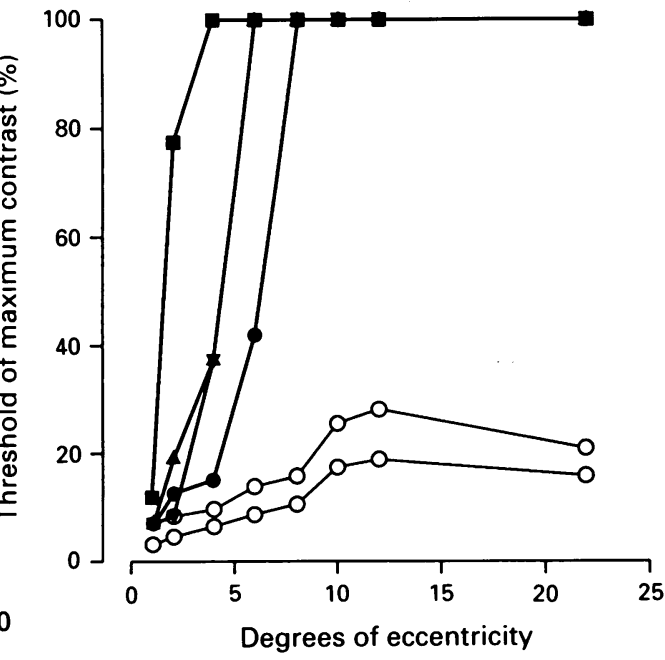

o Normals $\bullet \mathrm{V} / 7 \quad \bullet \mathrm{V} / 6 \Delta \mathrm{V} / 2 \quad \nabla \mathrm{V} / 9$

Figure 5 Colour contrast sensitivity plots of the protan axis from affected patients. Beyond $6^{\circ}$ of eccentricity, none of the patients were able to identify coloured images at $100 \%$ contrast between image and background.

outside the central $10^{\circ}$ of visual field in all patients tested, and by the late twenties, profound photoreceptor sensitivity threshold elevations were recorded as close as $3^{\circ}$ from fixation. Cone dysfunction occurred concomitantly with rod dysfunction but was slightly less severe, the sensitivity of central cones in light adapted conditions being less depressed than in dark adapted conditions. This is explained by the persistence of cone-mediated contrast detection in the photopic state, but a loss of absolute cone sensitivity in the scotopic state. Colour contrast sensitivity testing detected abnormal pericentral cone function in areas where rod and cone sensitivities were thought to be relatively normal based upon static perimetric and adaptometric testing. The flash electroretinogram responses were reduced to a minimal cone response in three patients and extinguished in the fourth.

The areas of scotopic and photopic sensitivity loss are generally the same implying that both rods and cones are affected by disease. The data do not make it clear whether both photoreceptor classes are affected primarily or the cones are lost as a consequence of demise of rods. This distinction formed the theoretical basis for the division between the two classes of dominant disease. ${ }^{32-34}$ In those subjects with residual function sufficient to make measurement reliable it appears that the photopic system was less involved than the scotopic implying the possibility that cones may be lost as a secondary event.

Because peripherin-rds is expressed in both rods and cones, it is feasible that both rod and cone photoreceptor function are primarily affected by this mutation. To date, five mutations in the RDS gene have been identified which are associated with autosomal dominant retinitis pigmentosa phenotypes. ${ }^{1+152122}$ In four of these, cone responses in young affected patients were significantly delayed and moderately reduced in amplitude. Furthermore, four additional RDS gene mutations, each with proved autosomal dominant inheritance have been identified as causing macular dystrophy. ${ }^{21}{ }^{23}$ Affected patients with profound loss of both photopic and scoto function. Isolated rod and cone sensitivities under all conditions were markedly abnormal 


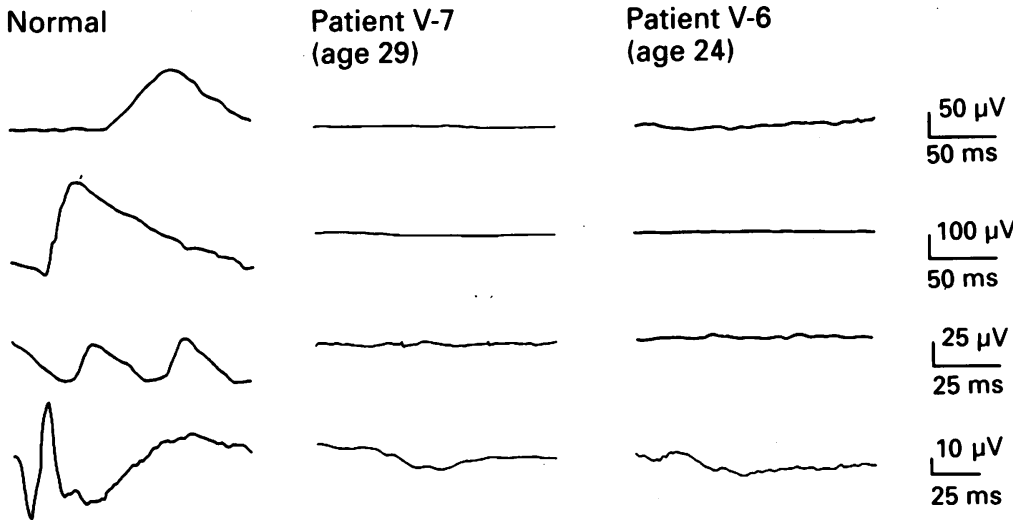

Figure 6 Electroretinographic data from patients $V-6$ and $V-7$. Upper row: blue $460 \mathrm{~nm}$ flash semisaturating for rods. Second row: intense blue flash, with rod and cone activity. Third row: $30 \mathrm{~Hz}$ flicker. Fourth row: red $660 \mathrm{~nm}$ flash on green $550 \mathrm{~nm}$ background.

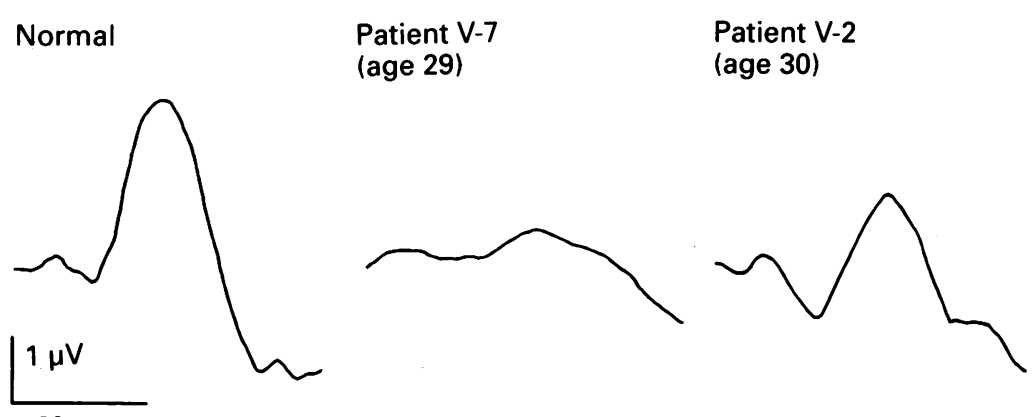

$.50 \mathrm{~ms}$

Figure 7 Pattern evoked electroretinograms from two patients. The P50 amplitude was reduced to below $25 \%$ of the normal value in patient $V-7$ and to $50 \%$ of the normal value in patient $V-2$. markedly from that of rhodopsin in that rhodopsin expresses only in rod photoreceptors. However, from our data there appears to be no fundamental difference in disease caused by the codon 118 mutation in this family when compared with retinal dystrophy consequent upon some rhodopsin mutations.

This study was supported by MRC, UK grant G9326194N, the American RP Foundation, and the British Retinitis Pigmentosa Society, UK.

1 Marmor MF, Aguire G, Arden GB, Berson E, Birch DB, Boughman JA, et al. Retinitis pigmentosa: a symposium on terminology and methods of examination. Ophthalmology 1983; 90: 126-31.

2 Heckenlively JR. Retinitis pigmentosa. In: Retinitis pigmentosa. Philadelphia: JB Lippincott, 1988: 1-5.

3 Jay $M$. On the hereditary of retinitis pigmentosa. $\mathrm{Br} \mathcal{J}$ Ophthalmol 1982; 66: 405-6.

4 Boughman JA, Conneally PM, Nance WE. Population genetic studies of retinitis pigmentosa. Am $\mathcal{F}$ Hum Genet 1980; 32: 223-5.

5 McWilliam P, Farrar GJ, Kenna P, Bradley DG, Humphries MM, Sharp EM, et al. Autosomal dominant retinitis pigmentosa (ADRP): localization of an ADRP gene to the pigmentosa (ADRP): localization of an ADRP gene to
long arm of chromosome 3. Genomics 1989; 5: 619-22.

6 Dryja TP, McGee TL, Reichel E, Hahn LB, Cowley GS, Yandell DW. A point mutation of the rhodopsin gene in one form of retinitis pigmentosa. Nature 1990; 343: $364-6$.

7 Dryja TP, McGee TL, Hah LB, Cowley GS, Olsson JE, Reichel E, et al. Mutations within the rhodopsin gene in patients with autosomal dominant retinitis pigmentosa. NEnglf Med 1990; 323: 1302-7.

8 Sung $\mathrm{CH}$, Davenport CM, Hennessey JC, Maumenee $\mathrm{H}$, Jacobson SG, Heckenlively JR, et al. Rhodopsin mutations in autosomal dominant retinitis pigmentosa. Proc Nat Acad in autosomal domina 1991 88: 6481-5.

9 Keen TJ, Inglehearn CF, Lester DH, Bashir R, Jay M, Bird AC, et al. Autosomal dominant retinitis pigmentosa: four new mutations in rhodopsin, one of them at the retinal attachment site. Genomics 1991; 11: 199-205.

10 Inglehearn CF, Keen TJ, Bashir R, Jay M, Fitzke FW, Bird AC. A completed screen for mutations of the rhodopsin gene in a panel of patients with autosomal dominant retinitis pigmentosa. Hum Mol Genet 1992; 1: 41-5.

11 Lester DH, Inglehearn CF, Bashir R, Ackford H, Esakawitz $\mathrm{L}$, Jay M, et al. Linkage to D3S47 (C17) in one large dominant retinitis family and exclusion in another: confirmation of genetic heterogeneity. Am ₹ Hum Genet 1990; 47: mation of

with either of the arginine 172 mutations demonstrated central rod and cone sensitivity loss, there being some evidence to suggest that the cones may be a primary target of disease. . $^{35}$

The putative function of peripherin-rds may provide an explanation for the differential involvement of both rods and cones with different mutations. Peripherin-rds is a photoreceptor protein with a primary structure of 346 amino acids, four transmembrane hydrophobic domains, and $2 \mathrm{~N}$-linked glycosylation sites, one of which is conserved across four species. ${ }^{196} \mathrm{It}$ is believed to be important to the physical structure of the outer segments, and may be responsible for the stability of the edge of the discs or maintenance of the parallel arrangement of the outer segment membranes. ${ }^{37}$ It has been suggested that non-covalent bonding of peripherinrds to $R O M-1$, a rod specific protein structurally related to peripherin-rds may be important in rods but this cannot be the case in cones since ROM-1 is found only in rods. ${ }^{38}$ Therefore, it is conceivable that a mutation which would interfere with the binding of ROM-1 would disrupt rod structure but not that of cones. Such a distinction does not explain the pathogenesis of central and peripheral degenerations, unless functional differences exist between central and peripheral photoreceptors with respect to peripherin-rds. Such differences have yet to be sought. Consequently, a mutation of the RDS gene could theoretically alter the structural stability of rods or cones alone, or both, and produce many different phenotypes.

The expression of the RDS gene differs
12 Blanton SH, Heckenlively JR, Cottingham AW, Friedman LH, Daiger SP. Linkage mapping of autosomal dominant retinitis pigmentosa (RP1) to the pericentric
human chromosome 8 . Genomics $1991 ; 11: 857-69$.

13 Farrar GJ, Jordan SA, Kenna P, Humphries MM, KumarSingh R, McWilliam P, et al. Autosomal dominant retinitis pigmentosa; localization of a disease gene (RP6) to the short arm of chromosome 6. Genomics 1991; 11: 870-4.

14 Farrar GJ, Kenna P, Jordan SA, Kumar-singh R, Humphries MM, Sharp EM. A three-base-pair deletion in the peripherin-RDS gene in one form of retinitis pigmentosa. Nature 1991; 354: 478-80.

15 Kajiwara K, Hahn LB, Mukai S, Travis GH, Berson EL, Dryja TP. Mutations in the human retinal degeneration slow gene in autosomal dominant retinitis pigmentosa. Nature gene in autosoma

16 Travis GH, Brennan MB, Danielson PE, Kozak CA, Sutcliffe JG. Identification of a photoreceptor-specific mRNA encoded by the gene responsible for retinal degeneration slow (rds). Nature 1989; 338: 70-3.

17 Connell G, Boscom R, McInnes R, Molday L. Photoreceptor cell peripherin is the normal product of the gene responsible
for the retinal degeneration in the rds mouse. Proc Natl for the retinal degeneration

18 Connell G, Molday RS. Molecular cloning, primary structure and orientation of the vertebrate photoreceptor cell protein peripherin in the rod disc membrane. Biochemistry 1990; 29: 4691-8.

19 Travis G, Sutcliffe JG, Bok D. The retinal degeneration slow (rds) gene product is a photoreceptor disc membrane associated glycoprotein. Neuron 1991; 6: 61-70.

20 Arokawa K, Molday LL, Molday RS, Williams DS. Localization of peripherin/rds in the disk membranes of cone and rod photoreceptors; relationship to disc membrane morphogenesis and retinal degeneration. F Cell Biol 1992; 116: 659genes.

21 Wells JA, Wroblewski JJ, Keen J, Ingelhearn C Jubb C, Eckstein A. Mutations in the human retinal degeneration
slow (RDS) gene can cause either retinitis pigmentosa or slow (RDS) gene can cause either retinitis pigm
macular dystrophy. Nature Genet 1993; 3: 213-8.

22 Kajiwara K, Sandberg MA, Berson EL, Dryja TP. A null mutation in the human peripherin/RDS gene in a family with autosomal dominant retinitis punctata albescens. Nature Genet 1993; 3: 208-12.

23 Nichols BE, Sheffield VC, Vandenburgh K, Drak AV, Kimura AE, Stone EM. Butterfly-shaped pigment dystrophy of the fovea caused by a point mutation in codon 167 of the RDS gene. Nature Genet 1993; 3: 202-7. 
24 Keen TJ, Lester DH, Inglehearn CF, Curtis A, Bhattacharya SS. Rapid detection of single base mismatches as heteroSS. Rapid detection of single base mismatches as hetero
duplexes on hydrolink gels. Trends Genet 1991; 7: 5-10.

25 Jacobson SG, Voight WJ, Parel JM, Apathy PP, NghiemPhy L, Myers SW, et al. Automated light- and darkadapted perimetry for evaluating retinitis pigmentosa. Ophthalmology 1986; 93: 1604-11.

26 Ernst W, Faulkner DS, Hogg CR, Powell DJ, Arden GB, Vaegan. An automated static perimeter/adaptometer using light emitting diodes. Brf Ophthalmol 1983;67: 431-42.

27 Arden GB, Gunduz K, Perry S. Colour vision testing with a computer system. Clin Vis Sci 1988; 2: 303-20.

28 Marmor MF, Calif S, Arden GB, Nilson SE, Zrenner E. Standard for clinical electroretinography. Arch Ophthalmol 1989; 107: 816-9.

29 Arden GB, Carter RM, Hogg CR, Powell DJ, Ernst W, Clover $\mathrm{GM}$, et al. A modified ERG technique and the results obtained in X-linked retinitis pigmentosa. Br $\mathcal{F}$ Ophthalmol 1983; 67: 419-30

30 Spileers W, Falcao-Reis F, Hogg C, Arden GB. The human ERG evoked by a Ganzfield stimulator powered by red and green light emitting diodes. Clin Vis Sci 1993; 8: 21-39.

31 Arden GB, Vaegan. Electroretinograms evoked in man by local uniform and pattern stimulation. $\mathcal{F}$ Physiol 1983; 341 . 85-104.

32 Massof RW, Finkelstein D. Two forms of autosomal dominant retinitis pigmentosa. Doc Ophthalmol 1981; 51: 289-346.
33 Lyness AL, Ernest W, Quinlan MP, Clover GM, Arden GB, Carter RM. A clinical, psychophysical and electroretinoCarter RM. A clinical, psychophysical and electroretinographic survey of patients with autosomal domi

34 Arden GB, Carter RM, Hogg CR, Powell DJ, Ernst W, Clover GM. Rod and cone activity in patients with dominantly inherited retinitis pigmentosa: comparisons between psychophysical and electroretinographic measurements. Brf Ophthalmol 1983; 67: 405-18.

35 Wroblewski JJ, Wells JA, Eckstein A, Fitzke FW, Jubb C, Keen J. Macular dystrophy associated with mutations at codon 172 in the human retinal degeneration slow (RDS) gene. Ophthalmology (in press).

36 Travis GH, Christerson L, Danielson PE, Dryja TP, Sutcliffe JG. The human retinal degeneration slow (RDS) gene: chromosome assignment and structure of the mRNA. chromosome assignment and

37 Arokawa K, Molday MM, Molday RS, Williams DS. Localization of peripherin/rds in the disk membranes of cone and rod photoreceptors; relationship to disk membrane morphogenesis and retinal degeneration. $\mathcal{F}$ Cell Biol 1992; 116: $659-67$.

38 Bascom RA, Manora S, Collins L, Molday RS, Kalnins VI, McInnes RR. Molecular cloning of the cDNA for a novel photoreceptor-specific membrane (ROM-1) identifies a disk rim protein family implicated in human degenerative retinopathies. Neuron 1992;8: 1171-84. 